\title{
Performance of current ultrasound-based malignancy risk stratification systems for thyroid nodules in patients with follicular neoplasms
}

\author{
Yinghe Lin ${ }^{1,2} \cdot$ Shuiqing Lai ${ }^{1}$ Peiqing Wang ${ }^{1,3} \cdot$ Jinlian $\mathrm{Li}^{1,2} \cdot$ Zhijiang Chen $^{1} \cdot$ Long Wang $^{1} \cdot$ Haixia Guan ${ }^{1}$. \\ Jian Kuang ${ }^{1} \mathbb{D}$
}

Received: 13 August 2021 / Revised: 28 October 2021 / Accepted: 29 October 2021 / Published online: 1 January 2022

(c) The Author(s) 2021

\begin{abstract}
Objectives To investigate the ability of the currently used ultrasound-based malignancy risk stratification systems for thyroid neoplasms (ATA, AACE/ACE/AME, K-TIRADS, EU-TIRADS, ACR-TIRADS and C-TIRADS) in distinguishing follicular thyroid carcinoma (FTC) from follicular thyroid adenoma (FTA). Additionally, we evaluated the ability of these systems in correctly determining the indication for biopsy.

Methods Three hundred twenty-nine follicular neoplasms with definitive postoperative histopathology were included. The nodules were categorized according to each of six stratification systems, based on ultrasound findings. We dichotomized nodules into the positive predictive group of FTC (high and intermediate risk) and negative group of FTC based on the classification results. Missed biopsy was defined as neoplasms that were diagnosed as FTCs but for which biopsy was not indicated based on lesion classification. Unnecessary biopsy was defined as neoplasms that were diagnosed as FTAs but for whom biopsy was considered indicated based on classification. The diagnostic performance and missed and unnecessary biopsy rates were evaluated for each stratification system.

Results The area under the curve of each system for distinguishing follicular neoplasms was $<0.700$ (range, $0.511-0.611$ ). The missed biopsy rates were 9.0-22.4\%. The missed biopsy rates for lesions $\leq 4 \mathrm{~cm}$ and lesions sized $2-4 \mathrm{~cm}$ were $16.2-$ $35.1 \%$ and $0-20.0 \%$, respectively. Unnecessary biopsy rates were $65.3-93.1 \%$. In $\leq 4 \mathrm{~cm}$ group, the unnecessary biopsy rates were $62.2-89.7 \%$.

Conclusion The malignancy risk stratification systems can select appropriate nodules for biopsy in follicular neoplasms, while they have limitations in distinguishing follicular neoplasms and reducing unnecessary biopsy. Specific stratification systems and recommendations should be established for follicular neoplasms.

\section{Key Points}

- Current ultrasound-based malignancy risk stratification systems of thyroid nodules had low efficiency in the characterization of follicular neoplasms.

- The adopted stratification systems showed acceptable performance for selecting FTC for biopsy but unsatisfactory performance for reducing unnecessary biopsy.
\end{abstract}

Keywords Thyroid neoplasms · Thyroid cancer, follicular · Ultrasonography $\cdot$ Biopsy, fine-needle

Haixia Guan and Jian Kuang have equal contributions.

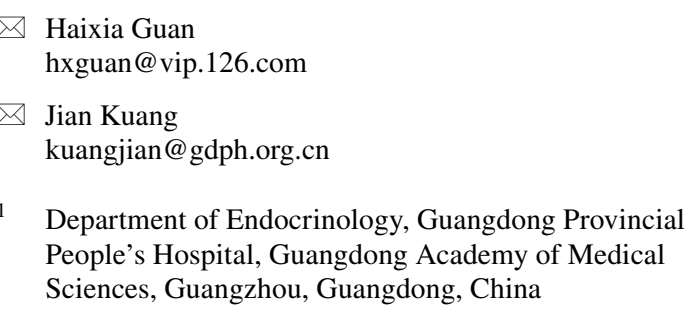

2 The Second School of Clinical Medicine, Southern Medical University, Guangzhou, Guangdong, China

3 Shantou University Medical College, Shantou, Guangdong, China 


\section{Abbreviations}

2015 ATA

AACE/ACE/AME American Association of Clinical Endocrinologists, American College of Endocrinology, and Associazione Medici Endocrinology Medical Guidelines for Clinical Practice for the Diagnosis and Management of Thyroid Nodules (2016 Update)

ACR-TIRADS American College of Radiology Thyroid Imaging Reporting and Data System
AUC

AUS

CI

C-TIRADS

EU-TIRADS

FLUS

FN

FNA

FTA

FTC

K-TIRADS

NPV

PPV

PTC

SD

SFN

TIRADS

Areas under the receiving operator characteristics curve

Atypia of undetermined significance

Confidence intervals

2020 Chinese Guidelines for Ultrasound Malignancy Risk Stratification of Thyroid Nodules

European Thyroid Association Guidelines for Ultrasound Malignancy Risk Stratification of Thyroid Nodules in Adults

Follicular lesion of undetermined significance

Follicular neoplasm

Fine-needle aspiration

Follicular thyroid adenoma

Follicular thyroid carcinoma

Revised Korean Society of Thyroid

Radiology Consensus Statement and

Recommendations

Negative predictive value

Positive predictive value

Papillary thyroid carcinoma

Standard deviation

Suspicious for a follicular neoplasm

Thyroid Imaging Reporting and Data System

\section{Introduction}

Both follicular thyroid adenoma (FTA) and follicular thyroid carcinoma (FTC) originate from follicular cells [1]. FTC is the second most common thyroid malignancy accounting for $10-15 \%$ of all malignant thyroid tumors. FTC shows a high propensity for hematogenous spread and $15 \%$ to $27 \%$ of these patients develop distant metastasis [2,3]. Compared with papillary thyroid carcinoma (PTC), which is the most common subtype of thyroid cancer (approximately 80\%), patients with FTC have a twofold higher risk of lung metastasis and tenfold higher risk of bone metastasis resulting in worse survival outcomes $[2,4,5]$. However, preoperative differentiation of FTC from its benign counterpart (FTA) is an inherently challenging aspect of management of thyroid nodules.

Ultrasound is the first-line imaging tool to evaluate the risk of malignancy and for formulating the optimal management strategy, including determining the indication for fineneedle aspiration (FNA), and informing treatment decisionmaking (surgical resection, monitoring, or no follow-up) [6]. Use of a single parameter for ultrasound evaluation may lead to inter-observer variability resulting in suboptimal sensitivity and specificity [7]. To standardize the evaluation of malignant thyroid nodules, various clinical societies have recently developed ultrasound-based malignancy risk stratification systems [8-13]. Based on the different versions of the Thyroid Imaging Reporting and Data System (TIRADS), several "pattern-based" systems and "score-based" systems have been established. The former are represented by 2015 ATA (American Thyroid Association), AACE/ACE/AME (American Association of Clinical Endocrinologists, American College of Endocrinology, and Associazione Medici Endocrinology), K-TIRADS (Korean Society of Thyroid Radiology), and EU-TIRADS (European Thyroid Association). The latter include ACR-TIRADS (American College of Radiology) and C-TIRADS (2020 Chinese Guidelines for Ultrasound Malignancy Risk Stratification of Thyroid Nodules). All these systems have shown reliable performance for the diagnosis and for selecting candidates for FNA [14-17].

As mentioned above, there are considerable differences in the incidence rates of various thyroid cancer subtypes [2]. In previous studies that evaluated these systems, the vast majority of malignant specimens were PTCs (88.9 to 99.6\%) [18], which may have introduced an element of bias. Ultrasonographic features of FTC and PTC are considerably different [3]. The established malignant features, including hypoechogenicity, irregular margins, microcalcifications, and nonparallel orientation, are more common in PTC than in FTC.

Currently, few studies have focused on the value of ultrasound-based malignancy risk stratification systems in patients with follicular neoplasms [19-21]. The performance of these systems in distinguishing FTC from FTA and in correctly determining the indications for biopsy is uncertain. Thus, we hypothesized that the relevant conclusions reported in the past could not be simply extrapolated to follicular tumors.

In this study, we aimed to investigate the performance of the currently used systems in the context of follicular neoplasms. For this purpose, we compared the ability of the current systems in distinguishing FTC from FTA. Additionally, 
we assessed whether these systems can help identify the nodules that require a biopsy and can reduce the rate of unnecessary biopsies.

\section{Materials and methods}

This retrospective study was approved by the Institutional Review Board, and the requirement for informed consent to review images and medical records was waived.

\section{Patients}

From January 2014 to May 2020, 441 consecutive patients (455 nodules) with thyroid follicular neoplasms proven by histopathological examination of the surgical specimens following thyroidectomy at a tertiary referral center were included in this study. Fourteen patients were pathologically confirmed to have two lesions each (4 with FTCs and 10 with FTAs). For these patients, the larger nodule among the two lesions was selected. The exclusion criteria were as follows: absence of preoperative thyroid US images $(n=55)$; uncertain match between imaging findings and histopathological results $(n=8)$. Because hyperfunctioning nodules do not require FNA [8], definitive or suspected hot nodules were also excluded $(n=49)$.

\section{Ultrasonography}

Ultrasonography examinations of thyroid glands and cervical regions were performed with Aplio 500 (Toshiba Medical System), HI Vision Ascendus (Hitachi Medical Corporation), or HI Vision Preirus (Hitachi Medical Corporation) ultrasound instruments equipped with $5-12-\mathrm{MHz}$ linear array transducers. The following ultrasound features of each neoplasm were recorded and reviewed by 2 researchers who were blinded to the diagnosis: maximum diameter (cm); location (left, right, or isthmus); composition (spongiform, cystic, mixed, or solid); echogenicity (anechoic, hyperechoic, isoechoic, hypoechoic, or very hypoechoic); margin (smooth, ill-defined, or irregular); calcification (absent, microcalcification, macrocalcification, or rim calcification); shape (round to oval or irregular); orientation in transverse view (parallel or nonparallel); hypoechoic peripheral halo (absence or presence); vascularization (absent, perinodular, intranodular, or mixed); and the location of the solid component for mixed-content nodules (eccentric or non-eccentric). The presence of other hyperechoic foci (comet-tail artifacts or indeterminate), extrathyroidal extension, and suspicious cervical lymph node was also investigated. Any disagreement between the 2 researchers with respect to these features was resolved by consensus.

\section{Categorization according to the risk stratification systems}

Based on retrospective analysis of ultrasound features, each thyroid nodule was categorized using the six stratification systems: 2015 ATA, AACE/ACE/AME, K-TIRADS, EUTIRADS, ACR-TIRADS, and C-TIRADS [8-13]. For statistical analysis, firstly, the nodules were dichotomized into the positive predictive group of FTC (high and intermediate suspicion according to 2015 ATA; high and intermediate risk according to AACE/ACE/AME; high and intermediate suspicion according to K-TIRADS; high and intermediate risk according to EU-TIRADS; category 4 and 5 according to ACR TI-RADS; category 4B to 5 according to C-TIRADS) and negative predictive group of FTC (benign, very low, and low suspicion according to 2015 ATA; low risk according to AACE/ACE/AME; benign and low suspicion according to K-TIRADS; benign and low risk according to EU-TIRADS; category 1 to 3 according to ACR-TIRADS; category 2 to $4 \mathrm{~A}$ according to C-TIRADS).

Secondly, based on the risk stratification recommendations, the nodules were retrospectively divided into 2 categories: "indication for FNA" and "no indication for FNA" (Supplementary 1). Missed biopsy was defined as any case of FTC nodule for which FNA was not indicated based on the risk stratification system. Unnecessary biopsy was defined as any case of FTA for which FNA was considered indicated based on the risk stratification system. Missed biopsy rate and unnecessary biopsy rate were calculated for each of the six systems.

In addition, nodules that did not conform to any category according to the systems were included in the non-classifiable group. For non-classifiable nodules, FNA was only considered to be recommended if suspicious cervical lymph nodes were present.

\section{Data and statistical analysis}

Nominal and ordinal variables are expressed as frequencies and proportions, while continuous variables were expressed as mean \pm standard deviation (SD) and range. Betweengroup differences with respect to demographic, clinical, and ultrasound features were assessed using independent two-sample $t$ test or rank-sum test for continuous variables and chi-square test or Fisher's exact test for nominal variables. Data pertaining to the distribution of lesions in various categories according to the risk stratification systems were analyzed using Mann-Whitney $U$ test or Kruskal-Wallis test for ordinal variables. Based on the established cutoff, diagnostic performance of the systems was assessed using receiver operating characteristic (ROC) curve analysis. Sensitivity, specificity, positive predictive value (PPV), negative predictive value (NPV), and area under the ROC curves 
(AUC) were calculated with 95\% confidence intervals (95\% CI). AUCs of each system were compared using the DeLong method. Missed biopsy rates and unnecessary biopsy rates were compared using Cochran's Q test, respectively. All statistical analyses were performed using SPSS (version 23.0, IBM) or MedCalc software (version 19.0.4) software. Twosided $p$ values $<0.05$ were considered indicative of statistical significance.

\section{Results}

A total of 329 patients (329 nodules) were included in this study. These included $216(65.7 \%)$ women and 113 (34.3\%) men; the mean age of patients was $43.5 \pm 14.3$ years (range, $3-82)$.

\section{Baseline}

Of the 329 follicular neoplasms, 262 (79.6\%) were diagnosed as FTAs and 67 (20.4\%) were diagnosed as FTCs based on histopathological examination of surgical specimens The mean maximum diameter of the follicular neoplasms was $3.6 \pm 1.7 \mathrm{~cm}$ (range, 0.6-12.1). The most common ultrasound presentation of follicular neoplasm in our cohort was solid (76.3\%), isoechoic (79.0\%), smooth margin (92.1\%), non-calcification (85.7\%), round to oval (96.0\%), and parallel (99.7\%) nodule with peripheral halo (59.0\%) and mixed vascularization (93.1\%) (Table 1). There were no significant differences between FTA and FTC with respect to age, sex, maximum diameter, nodule location, orientation, peripheral halo, extrathyroidal extension, or other hyperechoic foci (comet-tail artifacts or indeterminate) $(p>0.05)$. However, there were significant differences with respect to following ultrasound features: hypoechoic $(15.3 \%$ vs $26.9 \%$, $p=0.026)$, ill-defined margin $(4.2 \%$ vs $20.9 \%, p<0.001)$, calcifications ( $10.7 \%$ vs $20.84 \%, p<0.001)$, microcalcifications $(3.1 \%$ vs $11.9 \%, p=0.003)$, irregular shape $(1.1 \%$ vs $14.9 \%, p<0.001)$, suspicious cervical lymph node $(0 \%$ vs $4.5 \%, p=0.008)$, and the location of the solid component in mixed-content nodules $(25.4 \%$ vs $80.0 \%, p=0.023)$ (detailed comparisons among FTC subtypes in Supplementary 2).

The most frequent classification was low suspicion by 2015 ATA (64.7\%), intermediate risk by AACE/ACE/AME $(89.0 \%)$, low suspicion by K-TIRADS (78.5\%), low risk by EU-TIRADS (76.5\%), TR3 by ACR-TIRADS (56.3\%), and TR4A by C-TIRADS (68.1\%) (Table 1). Statistical comparisons between FTA and FTC showed significant differences in distributions according to the six systems respectively, while no significant difference was found among FTC subtypes (Table 2).

\section{Performance of the stratification systems}

The diagnostic indices of the six systems depending on predictive classifications are presented in Table 3. The AUCs for the six systems ranged from 0.511 to 0.611 . K-TIRADS, EUTIRADS, ACR-TIRADS, and C-TIRADS indicated statistical value for FTC $($ AUCs $=0.573-0.611, p<0.05)$. The AUC of C-TIRADS for differentiating FTC from FTA was the highest among all systems $(0.611 ; 95 \%$ CI, 0.556-0.664) (sensitivity: $26.9 \%$ (95\% CI, 16.8 to $39.1 \%$ ); specificity: $95.4 \%$ (95\% CI, 92.1 to $97.6 \%$ ); PPV: $60.0 \%$ (95\% CI, 43.2 to $74.7 \%$ ); NPV: $83.6 \%$ (95\% CI, 81.5 to $85.5 \%)$ ). AUCs of the statistical value systems were no significant difference $(p>0.05)$.

Notably, of the 27 non-classifiable nodules $(8.2 \%, 27$ of $329)$ according to 1 or more systems, 14 (20.9\%, 14 of 67$)$ were FTCs and $13(5.0 \%, 13$ of 262) were FTAs (Table 4). All cases were classifiable according to ACR-TIRADS and C-TIRADS.

The performance of the six systems in correctly determining the indication for biopsy and reducing unnecessary biopsy is shown in Table 5. The lowest missed biopsy rate was found with K-TIRADS (9.0\%), and the highest with ACR-TIRADS and AACE/ACE/AME (22.4\%). The missed biopsy rates were significantly different between the six systems $(p=0.049)$, but not in pairwise comparisons. ACR-TIRADS was associated with the lowest unnecessary biopsy rate (65.3\%), while K-TIRADS was associated with the highest unnecessary biopsy rate $(93.1 \%)$. The unnecessary biopsy rates were significantly different among the six systems $(p<0.001)$. The unnecessary biopsy rates of ACRTIRADS (65.3\%) and C-TIRADS (67.9\%) were lower than those of the other systems.

We further performed sub-group analysis based on nodule size. The missed biopsy rates for lesions $\leq 4 \mathrm{~cm}$ ranged from 16.2 to $35.1 \%$; the missed biopsy rates for lesions sized $2-4 \mathrm{~cm}$ ranged from 0 to $20.0 \%$; there was no significant difference between the six systems with respect to missed biopsy rate for lesions $\leq 4 \mathrm{~cm}$ or lesions sized $2-4 \mathrm{~cm}$ ( $p=0.135$ and $p=0.075$, respectively). The systems with the lowest and highest unnecessary biopsy rate for lesions $\leq 4 \mathrm{~cm}$ were ACR-TIRADS (62.2\%) and K-TIRADS (89.7\%), respectively. The unnecessary biopsy rates $(\leq 4 \mathrm{~cm})$ were significantly different among the six systems $(p<0.001)$. ACR-TIRADS $(62.2 \%)$ and C-TIRADS (70.5\%) had lower unnecessary biopsy rates than the other systems.

\section{Discussion}

Our study showed that the stratification systems did not help distinguish FTA from FTC. In addition, while the systems showed acceptable performance for correctly determining 
Table 1 Demographic

characteristics and ultrasound features of 329 follicular thyroid neoplasms

\begin{tabular}{|c|c|c|}
\hline \multicolumn{2}{|l|}{ Demographic characteristics } & No. $(\%)$ or mean $\pm \mathrm{SD}$ (range) \\
\hline \multicolumn{2}{|l|}{ Male } & $113(34.3)$ \\
\hline \multicolumn{2}{|l|}{ Age (years) } & $43.5 \pm 14.3(3-82)$ \\
\hline \multicolumn{3}{|l|}{ Pathological classifications } \\
\hline \multicolumn{2}{|l|}{ FTA } & $262(79.6)$ \\
\hline \multicolumn{2}{|l|}{ FTC } & $67(20.4)$ \\
\hline \multicolumn{2}{|l|}{ Minimally invasive } & $48(14.7)$ \\
\hline \multicolumn{2}{|l|}{ Encapsulated angioinvasive } & $12(3.6)$ \\
\hline \multicolumn{2}{|l|}{ Widely invasive } & $7(2.1)$ \\
\hline \multicolumn{3}{|l|}{ Ultrasound features } \\
\hline \multicolumn{2}{|l|}{ Maximum diameters $(\mathrm{cm})^{\mathrm{a}}$} & $3.6 \pm 1.7(0.6-12.1)$ \\
\hline \multicolumn{2}{|l|}{ Maximum diameters $>2 \mathrm{~cm}^{\mathrm{a}}$} & $285(86.9)$ \\
\hline \multicolumn{2}{|l|}{ Maximum diameters $>4 \mathrm{~cm}^{\mathrm{a}}$} & $135(41.2)$ \\
\hline \multirow[t]{3}{*}{ Location } & Left & $167(50.8)$ \\
\hline & Right & $157(47.7)$ \\
\hline & Isthmus & $5(1.5)$ \\
\hline \multirow[t]{5}{*}{ Composition } & Spongiform & $4(1.2)$ \\
\hline & Cystic & $0(0)$ \\
\hline & Mixed & $72(21.9)$ \\
\hline & Solid & $251(76.3)$ \\
\hline & Undetermined because of calcification & $2(0.6)$ \\
\hline \multirow[t]{5}{*}{ Echogenicity $^{\mathrm{c}}$} & Anechoic & $0(0)$ \\
\hline & Hyperechoic & $11(3.4)$ \\
\hline & Isoechoic & $260(79.0)$ \\
\hline & Hypoechoic & $58(17.6)$ \\
\hline & Very hypoechoic & $0(0)$ \\
\hline \multirow[t]{3}{*}{ Margin } & Smooth & $303(92.1)$ \\
\hline & Ill-defined & $25(7.6)$ \\
\hline & Irregular & $1(0.3)$ \\
\hline \multirow[t]{4}{*}{ Calcifications $^{\mathrm{b}}$} & Absent & $282(85.7)$ \\
\hline & Microcalcification & $16(4.9)$ \\
\hline & Macrocalcification & $26(7.9)$ \\
\hline & Rim calcification & $7(2.1)$ \\
\hline \multirow[t]{2}{*}{ Shape } & Round to oval & $316(96.0)$ \\
\hline & Irregular & $13(4.0)$ \\
\hline \multirow[t]{2}{*}{ Orientation } & Parallel & $328(99.7)$ \\
\hline & Nonparallel & $1(0.3)$ \\
\hline Peripheral halo & Present & $194(59.0)$ \\
\hline \multirow[t]{2}{*}{ Hyperechoic foci } & Comet-tail artifacts & $4(1.2)$ \\
\hline & Indeterminate & $3(0.9)$ \\
\hline Extrathyroidal extension & Present & $1(0.3)$ \\
\hline Suspicious cervical lymph node & Present & $3(0.9)$ \\
\hline \multirow{2}{*}{$\begin{array}{l}\text { The location of the solid compo- } \\
\text { nent for mixed-content nodules }\end{array}$} & Eccentric & $21(29.2)$ \\
\hline & Non-eccentric & $51(70.8)$ \\
\hline Vascularization & Absent & $11(3.3)$ \\
\hline & Perinodular & $6(1.8)$ \\
\hline & Intranodular & $6(1.8)$ \\
\hline & Mixed & $306(93.1)$ \\
\hline Ultrasound-based malignancy risk & stratification systems & \\
\hline ATA & Benign & $0(0)$ \\
\hline & Very low suspicion & $53(16.1)$ \\
\hline & Low suspicion & $213(64.7)$ \\
\hline
\end{tabular}


Table 1 (continued)

\begin{tabular}{|c|c|c|}
\hline Demographic characteristics & & No. $(\%)$ or mean $\pm \mathrm{SD}$ (range) \\
\hline & Intermediate suspicion & $37(11.3)$ \\
\hline & High suspicion & $8(2.4)$ \\
\hline & Nonclassifiable group & $18(5.5)$ \\
\hline \multirow[t]{4}{*}{ AACE/ACE/AME } & Low & $11(3.4)$ \\
\hline & Intermediate & $293(89.0)$ \\
\hline & High suspicion & $18(5.5)$ \\
\hline & Nonclassifiable group & $7(2.1)$ \\
\hline \multirow[t]{5}{*}{ K-TIRADS } & Benign (K-TR2) & $8(2.4)$ \\
\hline & Low suspicion (K-TR3) & $258(78.5)$ \\
\hline & Intermediate suspicion (K-TR4) & $53(16.1)$ \\
\hline & High suspicion (K-TR5) & $8(2.4)$ \\
\hline & Nonclassifiable group & $12(3.6)$ \\
\hline \multirow[t]{5}{*}{ EU-TIRADS } & Benign (EU-TR2) & $4(1.2)$ \\
\hline & Low risk (EU-TR3) & $252(76.5)$ \\
\hline & Intermediate risk (EU-TR4) & 38 (11.6) \\
\hline & High risk (EU-TR5) & $24(7.3)$ \\
\hline & Nonclassifiable group & $11(3.4)$ \\
\hline \multirow[t]{5}{*}{ ACR-TIRADS } & Benign (ACR-TR1) & $4(1.2)$ \\
\hline & Not suspicious (ACR-TR2) & $62(18.8)$ \\
\hline & Mildly suspicious (ACR-TR3) & $185(56.3)$ \\
\hline & Moderately suspicious (ACR-TR4) & $70(21.3)$ \\
\hline & Highly Suspicious (ACR-TR5) & $8(2.4)$ \\
\hline \multirow[t]{6}{*}{ C-TIRADS } & C-TR2 & $8(2.4)$ \\
\hline & C-TR3 & $67(20.4)$ \\
\hline & C-TR4A & $224(68.1)$ \\
\hline & C-TR4B & $19(5.8)$ \\
\hline & C-TR4C & $8(2.4)$ \\
\hline & C-TR5 & $3(0.9)$ \\
\hline
\end{tabular}

${ }^{a}$ The maximum diameters could not be determined in a case due to macrocalcifications

${ }^{\mathrm{b}}$ Some nodules presented multiple types of calcifications

${ }^{\mathrm{c}}$ Hyperechoic, isoechoic and hypoechoic: compared to adjacent parenchyma; very hypoechoic: more hypoechoic than strap muscles

Abbreviations: FTA follicular thyroid adenoma; FTC follicular thyroid carcinoma; ATA 2015 American Thyroid Association Management Guidelines for Adult Patients with Thyroid Nodules and Differentiated Thyroid Cancer; AACE/ACE/AME American Association of Clinical Endocrinologists, American College of Endocrinology, and Associazione Medici Endocrinology Medical Guidelines for Clinical Practice for the Diagnosis and Management of Thyroid Nodules (2016 Update); EU-TIRADS European Thyroid Association Guidelines for Ultrasound Malignancy Risk Stratification of Thyroid Nodules in Adults; K-TIRADS Revised Korean Society of Thyroid Radiology Consensus Statement and Recommendations; ACR-TIRADS American College of Radiology Thyroid Imaging Reporting and Data System; C-TIRADS 2020 Chinese Guidelines for Ultrasound Malignancy Risk Stratification of Thyroid Nodules

the indication for biopsy in FTC, the performance with respect to reducing unnecessary biopsy was unsatisfactory.

In this study, on using high or intermediate suspicious stratification as the positive cutoff for FTC, the AUCs of all six systems (0.511 to 0.611$)$ were less than 0.700 . A Korean study that focused on the performance of K-TIRADS in classifying follicular neoplasms found the low efficiency of K-TIRADS using the same cutoff (AUC $=0.575, p=0.439$ ) [19]. However, Liu et al reported acceptable performances of 2015 ATA $(\mathrm{AUC}=0.744$, $p<0.001)$ and ACR-TIRADS $(\mathrm{AUC}=0.744, p<0.001)$ for distinguishing follicular neoplasms [20]. In our study, AUCs of K-TIRADS, EU-TIRADS, ACR-TIRADS, and C-TIRADS were disappointing $(\mathrm{AUC}=0.573-0.611$, $p<0.05$ ). It may be difficult to improve clinical management of nodules based on these systems. The poor performance is attributable to the fact that follicular neoplasms present with substantially overlapping ultrasound features, and FTCs rarely present with features favoring malignancy as described in the current systems, such as nonparallel, 
Table 2 Distribution of follicular thyroid neoplasms among the ultrasound-based malignancy risk stratification systems

\section{FTA FTC $p \quad$ Minimally invasive Encapsulated Widely invasive $p$} angioinvasive

\begin{tabular}{|c|c|c|c|c|c|c|c|c|}
\hline \multicolumn{9}{|c|}{ Ultrasound-based malignancy risk stratification systems } \\
\hline \multirow[t]{6}{*}{ ATA } & Total classification & 251 & 60 & $p<0.001$ & 42 & 12 & 6 & $p=0.870$ \\
\hline & Benign & $0(0)$ & $0(0)$ & & $0(0)$ & $0(0)$ & $0(0)$ & \\
\hline & Very low suspicion & $52(20.7)$ & $1(1.7)$ & & $1(2.4)$ & $0(0)$ & $0(0)$ & \\
\hline & Low suspicion & $168(66.9)$ & $45(75.0)$ & & $31(73.8)$ & $9(75.0)$ & $5(83.3)$ & \\
\hline & Intermediate suspicion & $28(11.2)$ & $9(15.0)$ & & $7(16.7)$ & $1(8.3)$ & $1(16.7)$ & \\
\hline & High suspicion & $3(1.2)$ & $5(8.3)$ & & $3(7.1)$ & $2(16.7)$ & $0(0)$ & \\
\hline \multirow[t]{4}{*}{ AACE/ACE/AME } & Total classification & 260 & 62 & $p<0.001$ & 44 & 12 & 6 & $p=0.577$ \\
\hline & Low-risk & $10(3.8)$ & $1(1.6)$ & & $1(2.3)$ & $0(0)$ & $0(0)$ & \\
\hline & Intermediate-risk & $242(93.1)$ & $51(82.3)$ & & $37(84.1)$ & $9(75.0)$ & $5(83.3)$ & \\
\hline & High-risk & $8(3.1)$ & $10(16.1)$ & & $6(13.6)$ & $3(25.0)$ & $1(16.7)$ & \\
\hline \multirow[t]{5}{*}{ K-TIRADS } & Total classification & 261 & 66 & $p=0.002$ & 48 & 12 & 6 & $p=0.685$ \\
\hline & Benign & $8(3.1)$ & $0(0)$ & & $0(0)$ & $0(0)$ & $0(0)$ & \\
\hline & Low suspicion & $212(81.2)$ & $46(69.7)$ & & $32(66.7)$ & $9(75.0)$ & $5(83.3)$ & \\
\hline & Intermediate suspicion & $38(14.6)$ & $15(22.7)$ & & $13(27.0)$ & $1(8.3)$ & $1(16.7)$ & \\
\hline & High suspicion & $3(1.1)$ & $5(7.6)$ & & $3(6.3)$ & $2(16.7)$ & $0(0)$ & \\
\hline \multirow[t]{5}{*}{ EU-TIRADS } & Total classification & 256 & 62 & $p<0.001$ & 46 & 10 & 6 & $p=0.686$ \\
\hline & Benign & $4(1.6)$ & $0(0)$ & & $0(0)$ & $0(0)$ & $0(0)$ & \\
\hline & Low risk & $211(82.4)$ & $41(66.1)$ & & $31(67.4)$ & $7(70.0)$ & $3(50.0)$ & \\
\hline & Intermediate risk & $31(12.1)$ & $7(11.3)$ & & $5(10.9)$ & $1(10.0)$ & $1(16.7)$ & \\
\hline & High risk & $10(3.9)$ & $14(22.6)$ & & $10(21.7)$ & $2(20.0)$ & $2(33.3)$ & \\
\hline \multirow[t]{6}{*}{ ACR-TIRADS } & Total classification & 262 & 67 & $p<0.001$ & 48 & 12 & 7 & $p=0.736$ \\
\hline & ACR-TR1 & $4(1.5)$ & $0(0)$ & & $0(0)$ & $0(0)$ & $0(0)$ & \\
\hline & ACR-TR2 & $58(22.1)$ & $4(6.0)$ & & $4(8.3)$ & $0(0)$ & $0(0)$ & \\
\hline & ACR-TR3 & $148(56.6)$ & $37(55.2)$ & & $25(52.1)$ & $7(58.3)$ & $5(71.4)$ & \\
\hline & ACR-TR4 & 49 (18.7) & $21(31.3)$ & & $16(33.3)$ & $3(25.0)$ & $2(28.6)$ & \\
\hline & ACR-TR5 & $3(1.1)$ & $5(7.5)$ & & $3(6.3)$ & $2(16.7)$ & $0(0)$ & \\
\hline \multirow[t]{7}{*}{ C-TIRADS } & Total classification & 262 & 67 & $p<0.001$ & 48 & 12 & 7 & $p=0.075$ \\
\hline & C-TR2 & $8(3.1)$ & $0(0)$ & & $0(0)$ & $0(0)$ & $0(0)$ & \\
\hline & C-TR3 & $61(23.3)$ & $6(9.0)$ & & $6(12.5)$ & $0(0)$ & $0(0)$ & \\
\hline & C-TR4A & $181(69.1)$ & $43(64.2)$ & & $32(66.7)$ & $7(58.3)$ & $4(57.1)$ & \\
\hline & C-TR4B & $9(3.4)$ & $10(14.9)$ & & $6(12.5)$ & $2(16.7)$ & $2(28.6)$ & \\
\hline & C-TR4C & $3(1.1)$ & $5(7.5)$ & & $4(8.3)$ & $1(8.3)$ & $0(0)$ & \\
\hline & C-TR5 & $0(0)$ & $3(4.5)$ & & $0(0)$ & $2(16.7)$ & $1(14.3)$ & \\
\hline
\end{tabular}

Values are presented as number (\%)

Abbreviations: FTA follicular thyroid adenoma; FTC follicular thyroid carcinoma; ATA 2015 American Thyroid Association Management Guidelines for Adult Patients with Thyroid Nodules and Differentiated Thyroid Cancer; AACE/ACE/AME American Association of Clinical Endocrinologists, American College of Endocrinology, and Associazione Medici Endocrinology Medical Guidelines for Clinical Practice for the Diagnosis and Management of Thyroid Nodules (2016 Update); EU-TIRADS European Thyroid Association Guidelines for Ultrasound Malignancy Risk Stratification of Thyroid Nodules in Adults; K-TIRADS Revised Korean Society of Thyroid Radiology Consensus Statement and Recommendations; ACR-TIRADS American College of Radiology Thyroid Imaging Reporting and Data System; C-TIRADS 2020 Chinese Guidelines for Ultrasound Malignancy Risk Stratification of Thyroid Nodules

markedly hypoechoic, irregular margin, and microcalcifications $[3,22,23]$. A recent meta-analysis identified sonographic features for differentiating between FTA and FTC and found that tumor protrusion, presence of calcifications (irrespective of type), irregular margins, marked hypoechogenicity, and irregular shape were associated with high risk of FTC [24]. Our group found similar highrisk features, such as presence of calcifications $(10.7 \%$ vs $20.84 \%, p<0.001)$ and irregular shape $(1.1 \%$ vs $14.9 \%$, $p<0.001)$. Therefore, future systems may need to reassess the significance of these features in distinguishing follicular neoplasms. 
Table 3 Diagnostic indices of the systems for follicular thyroid neoplasms depending on predictive classifications. Classifiable nodules of each system were included

\begin{tabular}{lllllll}
\hline $\begin{array}{l}\text { Ultrasound-based malignancy } \\
\text { risk stratification systems }\end{array}$ & Sensitivity(\%) & Specificity(\%) & PPV(\%) & NPV(\%) & AUC & $p$ \\
\hline ATA & $23.3(13.4-36.0)$ & $87.7(82.9-91.5)$ & $31.1(20.4-44.3)$ & $82.7(80.5-84.7)$ & $0.555(0.498-0.611)$ & $p=0.062$ \\
AACE/ACE/AME & $98.4(91.3-99.9)$ & $3.84(1.9-7.0)$ & $19.6(19.0-20.3)$ & $90.9(56.6-98.7)$ & $0.511(0.455-0.567)$ & $p=0.266$ \\
K-TIRADS & $30.3(19.6-42.9)$ & $84.3(79.3-88.5)$ & $32.7(23.5-43.6)$ & $82.7(80.2-85.0)$ & $0.573(0.517-0.627)$ & $p=0.017^{\text {a }}$ \\
EU-TIRADS & $33.9(22.3-47.0)$ & $84.0(78.9-88.3)$ & $33.9(24.7-44.5)$ & $84.0(81.3-86.3)$ & $0.589(0.533-0.644)$ & $p=0.006^{\text {a }}$ \\
ACR-TIRADS & $38.8(27.1-51.5)$ & $80.2(74.8-84.8)$ & $33.3(25.4-42.4)$ & $83.7(80.7-86.2)$ & $0.595(0.540-0.648)$ & $p=0.004^{\text {a }}$ \\
C-TIRADS & $26.9(16.8-39.1)$ & $95.4(92.1-97.6)$ & $60.0(43.2-74.7)$ & $83.6(81.5-85.5)$ & $0.611(0.556-0.664)$ & $p<0.001^{\text {a }}$ \\
\hline
\end{tabular}

Numbers in parentheses are $95 \%$ confidence intervals

${ }^{a}$ There was no significant difference between the AUCs of the above four systems $(p>0.05)$

Abbreviations: PPV positive predictive value; NPV negative predictive value; ATA 2015 American Thyroid Association Management Guidelines for Adult Patients with Thyroid Nodules and Differentiated Thyroid Cancer; AACE/ACE/AME American Association of Clinical Endocrinologists, American College of Endocrinology, and Associazione Medici Endocrinology Medical Guidelines for Clinical Practice for the Diagnosis and Management of Thyroid Nodules (2016 Update); EU-TIRADS European Thyroid Association Guidelines for Ultrasound Malignancy Risk Stratification of Thyroid Nodules in Adults; K-TIRADS Revised Korean Society of Thyroid Radiology Consensus Statement and Recommendations; ACR-TIRADS American College of Radiology Thyroid Imaging Reporting and Data System; C-TIRADS 2020 Chinese Guidelines for Ultrasound Malignancy Risk Stratification of Thyroid Nodules

In addition, our study found that "pattern-based" systems (2015 ATA, AACE/ACE/AME, K-TIRADS, and EU-TIRADS) had more limitations in the classification of follicular neoplasms than previously reported in the literature [19-21], in contrast to the "score-based" systems (ACR-TIRADS and C-TIRADS). Given the limitations of pattern-based systems in the classification of follicular neoplasms, these systems should incorporate findings, such as undetermined composition, irregular shape, iso/hyperechoic with microcalcification and ill-defined margin (Table 4), or switch to "score-based" systems in the future.

In our cohort, the missed biopsy rates for all FTCs ranged from 9.0 to $22.4 \%$ and for FTCs $\leq 4 \mathrm{~cm}$ ranged from 16.2 to $35.1 \%$, which is concordant with the study by Castellana et al [21] in which 0 to $31 \%$ of FTCs were missed. Therefore, we believe that all six systems assessed in this study are effective tools to select FTC for FNA in clinical practice. In fact, previous studies have shown that follicular neoplasms are large [22-27]. The mean maximum diameter of FTC $(3.9 \pm 2.1 \mathrm{~cm})$ in our study was higher than any threshold proposed for ultrasound-based malignancy risk stratification systems. The highest maximum diameter was up to $12.1 \mathrm{~cm}$, which is the main reason for the high performance in selecting FTC for FNA. Besides, the size of FTC at the time of management is important. FTCs larger than $2 \mathrm{~cm}$ have a higher risk of distant metastasis and are associated with worse prognosis [28]. In our study, a satisfactory performance (0 to $20.0 \%$ ) was also seen for FTCs sized 2 to $4 \mathrm{~cm}$. Apart from unclassifiable nodules, missed FTCs were classified as category 2 and 3 by ACR-TIRADS, and as category 3 by C-TIRADS. There were 4 FTC lesions that were missed by both systems, including a solid isoechoic nodule and three mixed (predominantly solid) isoechoic nodules, which are generally considered indicative of benignity. Therefore, meticulous care should be exercised while managing non-high risk nodules as well.

However, correctly determining the indication for biopsy is only a step towards further diagnostic workup, since the definitive distinction between follicular neoplasms is only based on postoperative histopathology [3]. The risk of malignancy associated with a FNA reading of Bethesda IV (follicular neoplasm or suspicious for a follicular neoplasm) is $10-40 \%$ and that with Bethesda III (atypia of undetermined significance or follicular lesion of undetermined significance) is $6-18 \%$ [29]. The possibility of FTC in lesions with the above suspicious malignant cytological findings is uncertain. In previous studies, $10.8 \%$ follicular neoplasm (FN) and $1.2 \%$ follicular lesion of undetermined significance (FLUS) were eventually found to be FTCs [30, 31]. As an extreme example, 1379 thyroid nodules with FNA findings consistent with FN were not diagnosed as FTC after surgery [32]. Other studies have shown that the efficacy of TIRADS depends on the incidence of PTC in the study population [33] and that suspicious ultrasound features may not be useful in predicting malignancy of FLUS [34]. Therefore, due discretion is required due to the limitations of cytology in the diagnosis of FTC.

In previous studies involving papillary carcinoma as the primary malignant tumor, unnecessary biopsy rates with ultrasound-based malignancy risk stratification systems were generally lower than 50\% [14-17]. However, our study found higher unnecessary biopsy rates in patients with follicular neoplasm. In our study, FNA was considered indicated for $65.3 \%$ to $93.1 \%$ of all FTAs and for $62.2 \%$ to $89.7 \%$ of FTAs sized $\leq 4 \mathrm{~cm}$. We believe that this result is mainly due to the large size of follicular 
Table 4 Unclassifiable follicular thyroid neoplasms according to the ultrasound-based malignancy risk stratification systems

\begin{tabular}{|c|c|c|c|c|c|c|c|c|c|}
\hline \multirow[t]{2}{*}{ Nodule ID } & \multirow{2}{*}{$\begin{array}{l}\text { Pathological diag- } \\
\text { nosis }\end{array}$} & \multirow{2}{*}{$\begin{array}{l}\text { Ultrasound descrip- } \\
\text { tion }\end{array}$} & \multirow{2}{*}{$\begin{array}{l}\text { Maximum diameters } \\
(\mathrm{cm})\end{array}$} & \multicolumn{6}{|c|}{ Unclassified by } \\
\hline & & & & ATA & $\begin{array}{l}\text { AACE/ } \\
\text { ACE/AME }\end{array}$ & K-TIRADS & EU-TIRADS & ACR-TIRADS & C-TIRADS \\
\hline 4 & $\begin{array}{l}\text { FTC (minimally } \\
\text { invasive) }\end{array}$ & $\begin{array}{l}\text { Solid, hypoechoic, } \\
\text { ill-defined margin, } \\
\text { irregular shape, } \\
\text { macrocalcifications }\end{array}$ & 1.7 & $\mathrm{X}$ & $\mathrm{X}$ & & & & \\
\hline 23 & $\begin{array}{l}\text { FTC (minimally } \\
\text { invasive) }\end{array}$ & $\begin{array}{l}\text { Solid, hypoechoic, } \\
\text { ill-defined margin, } \\
\text { round to oval } \\
\text { shape, peripheral } \\
\text { halo }\end{array}$ & 2.7 & $\mathrm{X}$ & & & $\mathrm{X}$ & & \\
\hline 33 & $\begin{array}{l}\text { FTC (minimally } \\
\text { invasive) }\end{array}$ & $\begin{array}{l}\text { Solid, isoechoic, } \\
\text { smooth margin, } \\
\text { round to oval } \\
\text { shape, microc- } \\
\text { alcififications, } \\
\text { peripheral halo }\end{array}$ & 2.7 & $\mathrm{X}$ & & & & & \\
\hline 35 & $\begin{array}{l}\text { FTC (minimally } \\
\text { invasive) }\end{array}$ & $\begin{array}{l}\text { Solid, isoechoic, } \\
\text { ill-defined margin, } \\
\text { irregular shape, } \\
\text { peripheral calcifi- } \\
\text { cations, peripheral } \\
\text { halo }\end{array}$ & 4.1 & & $\mathrm{X}$ & & & & \\
\hline 36 & $\begin{array}{l}\text { FTC (widely inva- } \\
\text { sive) }\end{array}$ & $\begin{array}{l}\text { Solid, hypoechoic, } \\
\text { ill-defined margin, } \\
\text { irregular shape }\end{array}$ & 4.7 & & $\mathrm{X}$ & & & & \\
\hline 38 & $\begin{array}{l}\text { FTC (minimally } \\
\text { invasive) }\end{array}$ & $\begin{array}{l}\text { Solid, isoechoic, } \\
\text { ill-defined margin, } \\
\text { round to oval } \\
\text { shape, microc- } \\
\text { alcififications, } \\
\text { peripheral halo }\end{array}$ & 2.9 & $\mathrm{X}$ & & & & & \\
\hline 39 & $\begin{array}{l}\text { FTC (widely inva- } \\
\text { sive) }\end{array}$ & $\begin{array}{l}\text { Composition cannot } \\
\text { be determined } \\
\text { because of } \\
\text { macrocalcifica- } \\
\text { tions, present a } \\
\text { suspicious cervical } \\
\text { lymph node }\end{array}$ & $\begin{array}{l}\text { Undetermined } \\
\text { because of macro- } \\
\text { calcifications }\end{array}$ & $\mathrm{X}$ & & $\mathrm{X}$ & & & \\
\hline 41 & $\begin{array}{l}\text { FTC (minimally } \\
\text { invasive) }\end{array}$ & $\begin{array}{l}\text { Solid, hypoechoic, } \\
\text { smooth margin, } \\
\text { irregular shape, } \\
\text { peripheral halo }\end{array}$ & 2.0 & & $\mathrm{X}$ & & & & \\
\hline 42 & $\begin{array}{l}\text { FTC (minimally } \\
\text { invasive) }\end{array}$ & $\begin{array}{l}\text { Solid, hyperechoic, } \\
\text { smooth margin, } \\
\text { round to oval } \\
\text { shape, microc- } \\
\text { alcififications, } \\
\text { peripheral halo }\end{array}$ & 3.0 & $\mathrm{X}$ & & & & & \\
\hline 44 & $\begin{array}{l}\text { FTC (widely inva- } \\
\text { sive) }\end{array}$ & $\begin{array}{l}\text { Solid, isoechoic, } \\
\text { ill-defined margin, } \\
\text { round to oval } \\
\text { shape }\end{array}$ & 2.4 & & & & $\mathrm{X}$ & & \\
\hline 46 & $\begin{array}{l}\text { FTC (minimally } \\
\text { invasive) }\end{array}$ & $\begin{array}{l}\text { Solid, hypoechoic, } \\
\text { ill-defined margin, } \\
\text { round to oval } \\
\text { shape, macro- } \\
\text { calcifications, } \\
\text { peripheral halo }\end{array}$ & 2.7 & $\mathrm{X}$ & & & $\mathrm{X}$ & & \\
\hline 49 & $\begin{array}{l}\text { FTC (encapsulated } \\
\text { angioinvasive) }\end{array}$ & $\begin{array}{l}\text { Solid, isoechoic, } \\
\text { ill-defined margin, } \\
\text { round to oval } \\
\text { shape, peripheral } \\
\text { halo }\end{array}$ & 12.1 & & & & $\mathrm{X}$ & & \\
\hline
\end{tabular}


Table 4 (continued)

\begin{tabular}{|c|c|c|c|c|c|c|c|c|c|}
\hline \multirow[t]{2}{*}{ Nodule ID } & \multirow{2}{*}{$\begin{array}{l}\text { Pathological diag- } \\
\text { nosis }\end{array}$} & \multirow{2}{*}{$\begin{array}{l}\text { Ultrasound descrip- } \\
\text { tion }\end{array}$} & \multirow{2}{*}{$\begin{array}{l}\text { Maximum diameters } \\
(\mathrm{cm})\end{array}$} & \multicolumn{6}{|c|}{ Unclassified by } \\
\hline & & & & ATA & $\begin{array}{l}\text { AACE/ } \\
\text { ACE/AME }\end{array}$ & K-TIRADS & EU-TIRADS & ACR-TIRADS & C-TIRADS \\
\hline 61 & $\begin{array}{l}\text { FTC (encapsulated } \\
\text { angioinvasive) }\end{array}$ & $\begin{array}{l}\text { Solid, isoechoic, } \\
\text { ill-defined margin, } \\
\text { round to oval } \\
\text { shape, macrocalci- } \\
\text { fications }\end{array}$ & 5.7 & & & & $\mathrm{X}$ & & \\
\hline 94 & $\begin{array}{l}\text { FTC (minimally } \\
\text { invasive) }\end{array}$ & $\begin{array}{l}\text { Solid, hypoechoic, } \\
\text { smooth margin, } \\
\text { irregular shape }\end{array}$ & 5.7 & & $\mathrm{X}$ & & & & \\
\hline 73 & FTA & $\begin{array}{l}\text { Solid, isoechoic, } \\
\text { ill-defined margin, } \\
\text { round to oval } \\
\text { shape, macrocalci- } \\
\text { fications }\end{array}$ & 9.0 & & & & $\mathrm{X}$ & & \\
\hline 74 & FTA & $\begin{array}{l}\text { Solid, isoechoic, } \\
\text { ill-defined margin, } \\
\text { irregular shape, } \\
\text { microcalcififica- } \\
\text { tions }\end{array}$ & 2.0 & $\mathrm{X}$ & & & & & \\
\hline 81 & FTA & $\begin{array}{l}\text { Composition cannot } \\
\text { be determined } \\
\text { because of periph- } \\
\text { eral calcifications }\end{array}$ & 4.4 & $\mathrm{X}$ & $\mathrm{x}$ & $\mathrm{X}$ & & & \\
\hline 210 & FTA & $\begin{array}{l}\text { Solid, hypoechoic, } \\
\text { ill-defined margin, } \\
\text { round to oval } \\
\text { shape }\end{array}$ & 0.8 & $\mathrm{X}$ & & & $\mathrm{X}$ & & \\
\hline 223 & FTA & $\begin{array}{l}\text { Mixed, isoechoic, } \\
\text { ill-defined margin, } \\
\text { round to oval } \\
\text { shape, macro- } \\
\text { calcifications, } \\
\text { peripheral halo }\end{array}$ & 2.8 & & & & $\mathrm{X}$ & & \\
\hline 241 & FTA & $\begin{array}{l}\text { Solid, isoechoic, } \\
\text { smooth margin, } \\
\text { round to oval } \\
\text { shape, micro- } \\
\text { calcifications, } \\
\text { peripheral halo }\end{array}$ & 2.5 & $\mathrm{X}$ & & & & & \\
\hline 254 & FTA & $\begin{array}{l}\text { Solid, hypoechoic, } \\
\text { ill-defined margin, } \\
\text { round to oval } \\
\text { shape }\end{array}$ & 1.1 & $\mathrm{X}$ & & & $\mathrm{X}$ & & \\
\hline 275 & FTA & $\begin{array}{l}\text { Mixed, isoechoic, } \\
\text { smooth margin, } \\
\text { round to oval } \\
\text { shape, microcalci- } \\
\text { fications }\end{array}$ & 2.9 & $\mathrm{X}$ & & & & & \\
\hline 284 & FTA & $\begin{array}{l}\text { Solid, hypoechoic, } \\
\text { ill-defined margin, } \\
\text { irregular shape }\end{array}$ & 3.5 & $\mathrm{X}$ & $\mathrm{x}$ & & & & \\
\hline 293 & FTA & $\begin{array}{l}\text { Solid, hypoechoic, } \\
\text { ill-defined margin, } \\
\text { round to oval } \\
\text { shape, peripheral } \\
\text { calcifications }\end{array}$ & 1.1 & $\mathrm{X}$ & & & $\mathrm{X}$ & & \\
\hline 295 & FTA & $\begin{array}{l}\text { Solid, isoechoic, } \\
\text { ill-defined margin, } \\
\text { round to oval } \\
\text { shape, microcalci- } \\
\text { fications }\end{array}$ & 0.7 & $\mathrm{x}$ & & & & & \\
\hline 313 & FTA & $\begin{array}{l}\text { Solid, hypoechoic, } \\
\text { ill-defined margin, } \\
\text { round to oval } \\
\text { shape }\end{array}$ & 1.1 & $\mathrm{X}$ & & & $\mathrm{X}$ & & \\
\hline
\end{tabular}


Table 4 (continued)

\begin{tabular}{|c|c|c|c|c|c|c|c|c|c|}
\hline \multirow[t]{2}{*}{ Nodule ID } & \multirow{2}{*}{$\begin{array}{l}\text { Pathological diag- } \\
\text { nosis }\end{array}$} & \multirow{2}{*}{$\begin{array}{l}\text { Ultrasound descrip- } \\
\text { tion }\end{array}$} & \multirow{2}{*}{$\begin{array}{l}\text { Maximum diameters } \\
(\mathrm{cm})\end{array}$} & \multicolumn{6}{|c|}{ Unclassified by } \\
\hline & & & & ATA & $\begin{array}{l}\text { AACE/ } \\
\text { ACE/AME }\end{array}$ & K-TIRADS & EU-TIRADS & ACR-TIRADS & C-TIRADS \\
\hline 324 & FTA & $\begin{array}{l}\text { Mixed, isoechoic, } \\
\text { smooth margin, } \\
\text { round to oval } \\
\text { shape, microcalci- } \\
\text { fications }\end{array}$ & 4.1 & $\mathrm{X}$ & & & & & \\
\hline
\end{tabular}

A nodule was undetermined composition without any high-risk features, which could not be classified according to 2015 ATA, AACE/ACE/ AME and K-TIRADS

A nodule was undetermined composition with a suspicious cervical lymph node, which could not be classified according to 2015 ATA and K-TIRADS

Six nodules were irregular shape without any high-risk features, which could not be classified according to AACE/ACE/AME

Eight nodules were iso/hyperechoic with microcalcification, which could not be classified according to 2015 ATA

Eight solid nodules were hypoechoic with ill-defined margin, which could not be classified according to 2015 ATA

Eleven nodules were ill-defined margin without any high-risk features, which could not be classified according to EU-TIRADS

Abbreviations: FTA follicular thyroid adenoma; FTC follicular thyroid carcinoma; ATA 2015 American Thyroid Association Management Guidelines for Adult Patients with Thyroid Nodules and Differentiated Thyroid Cancer; AACE/ACE/AME American Association of Clinical Endocrinologists, American College of Endocrinology, and Associazione Medici Endocrinology Medical Guidelines for Clinical Practice for the Diagnosis and Management of Thyroid Nodules (2016 Update); EU-TIRADS European Thyroid Association Guidelines for Ultrasound Malignancy Risk Stratification of Thyroid Nodules in Adults; K-TIRADS Revised Korean Society of Thyroid Radiology Consensus Statement and Recommendations; ACR-TIRADS American College of Radiology Thyroid Imaging Reporting and Data System; C-TIRADS 2020 Chinese Guidelines for Ultrasound Malignancy Risk Stratification of Thyroid Nodules

neoplasms [22-27]. Furthermore, our study showed that the unnecessary biopsy rates with use of "pattern-based" systems were higher than those with use of "score-based" systems irrespective of the lesion size because of the different criteria for determining the indications for biopsy. According to "pattern-based" systems, FNA is not indicated only when nodules with special patterns exceed the above size threshold [8-11], such as entirely spongiform and pure cyst nodules $(3.3 \%$ and $0 \%$ of FTAs, respectively). In "score-based" systems [12, 13], FNA is not indicated for nodules that are classified as category 1 and 2 by ACR-TIRADS or as category 2 and 3 by C-TIRADS, irrespective of the size. In our study, a certain proportion of FTAs was categorized in the "no biopsy" group by the ACR-TIRADS and C-TIRADS (23.6\% and $26.4 \%$ of FTAs, respectively).

Currently, there is an impetus on reducing unnecessary biopsy of thyroid nodules, because of the low rate of malignancy and the generally good prognosis of the most common thyroid malignancy (PTC) [8]. Nevertheless, FTC exhibits a more aggressive biological behavior than PTC. Although the precise diagnosis of follicular neoplasms requires postoperative histopathology, preoperative biopsy and further molecular testing may provide supplementary information aiding the differential diagnosis of follicular neoplasms [35]. Thus, deliberately avoiding biopsy and further testing for follicular neoplasms require careful consideration. Recently, some studies have demonstrated the value of molecular testing for follicular neoplasms. For example, a study using next-generation sequencing reported that the presence of FLT3 and TP53 with no RET mutations was consistent with FTC and the absence of FLT3 and TP53 with the presence of RET mutations was consistent with FTA [36]. Another study investigating DNA methylation haplotype block markers identified 70 DNA methylation markers that were significantly different between the FTC and FTA samples [37].

There are several limitations of our study. First, this was a single-center retrospective study. Only patients with a confirmed postoperative diagnosis of thyroid follicular neoplasm were included. Patients who did not undergo surgery were missed, which may have introduced an element of selection bias. Additionally, 126 nodules (27.7\%, 126 of 455) were excluded which may also have resulted in selection bias. Finally, only non-dynamic images were available for recording the ultrasound features which may have affected the accuracy of data.

In conclusion, the currently used malignancy risk stratification systems for thyroid nodules showed poor ability in distinguishing FTA from FTC. The performance of these systems in selecting nodules for biopsy was acceptable, but the performance with respect to reducing unnecessary biopsy was unsatisfactory. Our findings indicate the need to develop a specific stratification system and recommendations for follicular neoplasms. 
Table 5 Ability of the ultrasound-based malignancy risk stratification systems to select proper nodules for biopsy and reduce unnecessary biopsy

\begin{tabular}{|c|c|c|c|c|c|c|}
\hline $\begin{array}{l}\text { Ultrasound-based } \mathrm{m} \\
\text { tion systems }\end{array}$ & lignancy risk stratifica- & Missed biopsy ${ }^{\mathrm{b}}$ & $\begin{array}{l}\text { Missed } \\
\text { biopsy } \\
(\leq 4 \mathrm{~cm})^{\mathrm{c}}\end{array}$ & $\begin{array}{l}\text { Missed } \\
\text { biopsy } \\
(2-4 \mathrm{~cm})^{\mathrm{d}}\end{array}$ & Unnecessary biopsy & $\begin{array}{l}\text { Unnecessary } \\
\text { biopsy }(\leq 4 \mathrm{~cm})^{\mathrm{f}}\end{array}$ \\
\hline ATA & Benign & $0 / 0(0)$ & $0 / 0(0)$ & $0 / 0(0)$ & $0 / 0(0)$ & $0 / 0(0)$ \\
\hline & Very low suspicion & $0 / 1(0)$ & $0 / 1(0)$ & $0 / 1(0)$ & $49 / 52(92.3)$ & $24 / 27(88.9)$ \\
\hline & Low suspicion & $3 / 45(6.7)$ & $3 / 23(13.0)$ & $0 / 17(0)$ & $161 / 168(95.8)$ & 90/97 (92.8) \\
\hline & Intermediate suspicion & $1 / 9(11.1)$ & $1 / 4(25.0)$ & $0 / 1(0)$ & $24 / 28(85.7)$ & $18 / 22(81.8)$ \\
\hline & High suspicion & $2 / 5(40.0)$ & $2 / 3(66.7)$ & $0 / 1(0)$ & $3 / 3(100)$ & $1 / 1(100)$ \\
\hline & Not classifiable & $6 / 7(85.7)^{\mathrm{a}}$ & $6 / 6(100)$ & $5 / 5(100)$ & $0 / 11(0)$ & $0 / 9(0)$ \\
\hline & Total & $12 / 67(17.9)$ & $12 / 37(32.4)$ & $5 / 25(20.0)$ & $237 / 262(90.5)$ & $133 / 156(85.3)$ \\
\hline AACE/ACE/AME & Low & $0 / 1(0)$ & $0 / 0(0)$ & $0 / 0(0)$ & $8 / 10(80.0)$ & $6 / 8(75.0)$ \\
\hline & Intermediate & $8 / 51(15.7)$ & $8 / 28(28.6)$ & $0 / 20(0)$ & $216 / 242(89.3)$ & $116 / 142(81.7)$ \\
\hline & High suspicion & $2 / 10(20.0)$ & $2 / 7(28.6)$ & $0 / 5(0)$ & $7 / 8(87.5)$ & $4 / 5(80.0)$ \\
\hline & Not classifiable & $5 / 5(100)$ & $2 / 2(100)$ & $0 / 0(0)$ & $0 / 2(0)$ & $0 / 1(0)$ \\
\hline & Total & $15 / 67(22.4)$ & $12 / 37(32.4)$ & $0 / 25(0)$ & $231 / 262(88.2)$ & $126 / 156(80.8)$ \\
\hline K-TIRADS & Benign & $0 / 0(0)$ & $0 / 0(0)$ & $0 / 0(0)$ & $4 / 8(50.0)$ & $4 / 7(57.1)$ \\
\hline & Low suspicion & $3 / 46(6.5)$ & $3 / 23(13.0)$ & $0 / 18(0)$ & 205/212 (96.7) & 107/114 (93.9) \\
\hline & Intermediate suspicion & $1 / 15(6.7)$ & $1 / 11(9.1)$ & $0 / 6(0)$ & $32 / 38(84.2)$ & $28 / 34(82.4)$ \\
\hline & High suspicion & $2 / 5(40.0)$ & $2 / 3(66.7)$ & $0 / 1(0)$ & $3 / 3(100)$ & $1 / 1(100)$ \\
\hline & Not classifiable & $0 / 1(0)^{\mathrm{a}}$ & $0 / 0(0)$ & $0 / 0(0)$ & $0 / 1(0)$ & $0 / 0(0)$ \\
\hline & Total & $6 / 67(9.0)$ & $6 / 37(16.2)$ & $0 / 25(0)$ & $244 / 262(93.1)$ & $140 / 156(89.7)$ \\
\hline EU-TIRADS & Benign & $0 / 0(0)$ & $0 / 0(0)$ & $0 / 0(0)$ & $0 / 4(0)$ & $0 / 4(0)$ \\
\hline & Low risk & $6 / 41(14.6)$ & $6 / 22(27.3)$ & $0 / 17(0)$ & 195/211 (92.4) & $100 / 116(86.2)$ \\
\hline & Intermediate risk & $1 / 7(14.3)$ & $1 / 4(25.0)$ & $0 / 1(0)$ & 26/31 (83.9) & $20 / 25(80.0)$ \\
\hline & High risk & $2 / 14(14.3)$ & $2 / 8(25.0)$ & $0 / 4(0)$ & $9 / 10(90.0)$ & $5 / 6(83.3)$ \\
\hline & Not classifiable & $5 / 5(100)$ & $3 / 3(100)$ & $3 / 3(100)$ & $0 / 6(0)$ & $0 / 5(0)$ \\
\hline & Total & $14 / 67(20.9)$ & $12 / 37(32.4)$ & $3 / 25(12.0)$ & $230 / 262(87.8)$ & $125 / 156(80.1)$ \\
\hline ACR-TIRADS & ACR-TR1 & $0 / 0(0)$ & $0 / 0(0)$ & $0 / 0(0)$ & $0 / 4(0)$ & $0 / 4(0)$ \\
\hline & ACR-TR2 & 4/4 (100) & $2 / 2(100)$ & $2 / 2(100)$ & $0 / 58(0)$ & $0 / 26(0)$ \\
\hline & ACR-TR3 & $8 / 37$ (21.6) & $8 / 19(42.1)$ & 2/13 (15.4) & $129 / 148(87.2)$ & 70/89 (78.7) \\
\hline & ACR-TR4 & $1 / 21(4.8)$ & $1 / 13(7.7)$ & $0 / 9(0)$ & $39 / 49$ (79.6) & $26 / 36(72.2)$ \\
\hline & ACR-TR5 & $2 / 5(40.0)$ & $2 / 3(66.7)$ & $0 / 1(0)$ & $3 / 3(100)$ & 1/1 (100) \\
\hline & Total & $15 / 67(22.4)$ & $13 / 37(35.1)$ & $4 / 25(16.0)$ & $171 / 262(65.3)$ & $97 / 156(62.2)$ \\
\hline C-TIRADS & C-TR2 & $0 / 0(0)$ & $0 / 0(0)$ & $0 / 0(0)$ & $0 / 8(0)$ & $0 / 7(0)$ \\
\hline & C-TR3 & $6 / 6(100)$ & 4/4 (100) & 4/4 (100) & 0/61 (0) & $0 / 24(0)$ \\
\hline & C-TR4A & $5 / 43(11.6)$ & $5 / 22(22.7)$ & $0 / 13(0)$ & 168/181 (92.8) & $103 / 116(88.8)$ \\
\hline & C-TR4B & $0 / 10(0)$ & $0 / 6(0)$ & $0 / 5(0)$ & 8/9 (88.9) & $5 / 6(83.3)$ \\
\hline & C-TR4C & $2 / 5(60.0)$ & $2 / 4(50.0)$ & $0 / 2(0)$ & $2 / 3(66.7)$ & $2 / 3(66.7)$ \\
\hline & C-TR5 & $0 / 3(0)$ & $0 / 1(0)$ & $0 / 1(0)$ & $0 / 0(0)$ & $0 / 0(0)$ \\
\hline & Total & $13 / 67$ (19.4) & $11 / 37(29.7)$ & $4 / 25(16.0)$ & 178/262 (67.9) & $110 / 156(70.5)$ \\
\hline
\end{tabular}

Values are presented as number $(\%)$

All $p$ values have been adjusted in pairwise comparisons

${ }^{a}$ No.39 (Table 4): an unclassifiable nodule with unknown size was indicated for FNA due to a suspicious cervical lymph node according to ATA and K-TIRADS

${ }^{\mathrm{b}}$ The missed biopsy rates were significantly different among the six systems $(p=0.049)$, but not found in pairwise comparisons

${ }^{\mathrm{c}}$ There was no significant difference between the six systems with respect to missed biopsy rate $(\leq 4 \mathrm{~cm})(p=0.135)$

${ }^{\mathrm{d}}$ There was no significant difference between the six systems with respect to missed biopsy rate $(2-4 \mathrm{~cm})(p=0.075)$

${ }^{\text {e}}$ The unnecessary biopsy rates were significantly different among the six systems $(p<0.001)$ : ACR-TIRADS vs. AACE/ACE/AME, $p<0.001$; ACR-TIRADS vs. EU-TIRADS, $p<0.001$; ACR-TIRADS vs. K-TIRADS, $p<0.001$; ACR-TIRADS vs. ATA, $p<0.001$; C-TIRADS vs. AACE/ ACE/AME, $p<0.001$; C-TIRADS vs. EU-TIRADS, $p<0.001$; C-TIRADS vs. K-TIRADS, $p<0.001$; C-TIRADS vs. ATA, $p<0.001$ 
Table 5 (continued)

${ }^{\mathrm{f}}$ The unnecessary biopsy rates $(\leq 4 \mathrm{~cm})$ were significantly different among the six systems $(p<0.001)$ : ACR-TIRADS vs. AACE/ACE/AME, $p<0.001$; ACR-TIRADS vs. EU-TIRADS, $p<0.001$; ACR-TIRADS vs. K-TIRADS, $p<0.001$; ACR-TIRADS vs. ATA, $p<0.001$; C-TIRADS vs. AACE/ACE/AME, $p=0.024$; C-TIRADS vs. EU-TIRADS, $p=0.046$; C-TIRADS vs. K-TIRADS, $p<0.001$; C-TIRADS vs. ATA, $p<0.001$; EU-TIRADS vs. K-TIRADS, $p=0.046$

Abbreviations: FNA fine-needle aspiration; FTA follicular thyroid adenoma; FTC follicular thyroid carcinoma; ATA 2015 American Thyroid Association Management Guidelines for Adult Patients with Thyroid Nodules and Differentiated Thyroid Cancer; $A A C E / A C E / A M E$ American Association of Clinical Endocrinologists, American College of Endocrinology, and Associazione Medici Endocrinology Medical Guidelines for Clinical Practice for the Diagnosis and Management of Thyroid Nodules (2016 Update); EU-TIRADS European Thyroid Association Guidelines for Ultrasound Malignancy Risk Stratification of Thyroid Nodules in Adults; K-TIRADS Revised Korean Society of Thyroid Radiology Consensus Statement and Recommendations; ACR-TIRADS American College of Radiology Thyroid Imaging Reporting and Data System; C-TIRADS 2020 Chinese Guidelines for Ultrasound Malignancy Risk Stratification of Thyroid Nodules

Supplementary Information The online version contains supplementary material available at https://doi.org/10.1007/s00330-021-08450-3.

Funding The authors state that this work has not received any funding.

\section{Declarations}

Guarantor The scientific guarantor of this publication is Jian Kuang.

Conflict of interest The authors of this manuscript declare no relationships with any companies whose products or services may be related to the subject matter of the article.

Statistics and biometry One of the authors has significant statistical expertise.

Informed consent Written informed consent was waived by the Institutional Review Board.

Ethical approval Institutional Review Board approval was obtained.

Methodology
-retrospective
-diagnostic or prognostic study/observational
-performed at one institution

Open Access This article is licensed under a Creative Commons Attribution 4.0 International License, which permits use, sharing, adaptation, distribution and reproduction in any medium or format, as long as you give appropriate credit to the original author(s) and the source, provide a link to the Creative Commons licence, and indicate if changes were made. The images or other third party material in this article are included in the article's Creative Commons licence, unless indicated otherwise in a credit line to the material. If material is not included in the article's Creative Commons licence and your intended use is not permitted by statutory regulation or exceeds the permitted use, you will need to obtain permission directly from the copyright holder. To view a copy of this licence, visit http://creativecommons.org/licenses/by/4.0/.

\section{References}

1. McHenry CR, Phitayakorn R (2011) Follicular adenoma and carcinoma of the thyroid gland. Oncologist 16:585-593

2. Achebrook-Kilfoy B, Grogan RH, Ward MH, Kaplan E, Devesa SS (2013) Follicular thyroid cancer incidence patterns in the United States, 1980-2009. Thyroid 23:1015-1021
3. Grani G, Lamartina L, Durante C, Filetti S, Cooper DS (2018) Follicular thyroid cancer and Hurthle cell carcinoma: challenges in diagnosis, treatment, and clinical management. Lancet Diabetes Endocrinol 6:500-514

4. Chow SM, Law SC, Au SK et al (2002) Differentiated thyroid carcinoma: comparison between papillary and follicular carcinoma in a single institute. Head Neck 24:670-677

5. Chow SM, Law SC, Mendenhall WM et al (2002) Follicular thyroid carcinoma: prognostic factors and the role of radioiodine. Cancer 95:488-498

6. Durante C, Grani G, Lamartina L, Filetti S, Mandel SJ, Cooper D (2018) The diagnosis and management of thyroid nodules: a review. JAMA 319:914-924

7. Choi SH, Kim EK, Kim SJ, Kwak JY (2014) Thyroid ultrasonography: pitfalls and techniques. Korean J Radiol 15:267

8. Haugen BR, Alexander EK, Bible KC et al (2016) 2015 American Thyroid Association Management Guidelines for Adult Patients with Thyroid Nodules and Differentiated Thyroid Cancer: the American Thyroid Association Guidelines Task Force on Thyroid Nodules and Differentiated Thyroid Cancer. Thyroid 26:1-133

9. Gharib H, Papini E, Garber JR et al (2016) American Association of Clinical Endocrinologists, American College of Endocrinology, and Associazione Medici Endocrinologi Medical Guidelines for Clinical Practice for the Diagnosis and Management of Thyroid Nodules-2016 Update. Endocr Pract 22:622-629

10. Shin JH, Baek JH, Chung J et al (2016) Ultrasonography diagnosis and imaging-based management of thyroid nodules: revised Korean Society of Thyroid Radiology Consensus Statement and Recommendations. Korean J Radiol 17:370-395

11. Russ G, Bonnema SJ, Erdogan MF, Durante C, Ngu R, Leenhardt L (2017) European Thyroid Association Guidelines for Ultrasound Malignancy Risk Stratification of Thyroid Nodules in Adults: The EU-TIRADS. Eur Thyroid J 6:225-237

12. Tessler FN, Middleton WD, Grant EG et al (2017) ACR Thyroid Imaging, Reporting and Data System (TI-RADS): white paper of the ACR TI-RADS Committee. J Am Coll Radiol 14:587-595

13. Zhou JQ, Yin LX, Wei X et al (2020) 2020 Chinese guidelines for ultrasound malignancy risk stratification of thyroid nodules: the C-TIRADS. Endocrine 70:256-279

14. Ospina NS, Iñiguez-Ariza NM, Castro MR (2020) Thyroid nodules: diagnostic evaluation based on thyroid cancer risk assessment. BMJ. https://doi.org/10.1136/bmj.16670

15. Castellana M, Castellana C, Treglia G et al (2020) Performance of five ultrasound risk stratification systems in selecting thyroid nodules for FNA. J Clin Endocrinol Metab. https://doi.org/10. 1210/clinem/dgz170

16. Kim PH, Suh CH, Baek JH, Chung SR, Choi YJ, Lee JH (2020) Unnecessary thyroid nodule biopsy rates under four ultrasound risk stratification systems: a systematic review and meta-analysis. Eur Radiol. https://doi.org/10.1007/s00330-020-07384-6 
17. Grani G, Lamartina L, Ascoli V et al (2019) Reducing the number of unnecessary thyroid biopsies while improving diagnostic accuracy: toward the "right" TIRADS. J Clin Endocrinol Metab 104:95-102

18 Trimboli P, Castellana M, Piccardo A et al (2020) The ultrasound risk stratification systems for thyroid nodule have been evaluated against papillary carcinoma. A meta-analysis. Rev Endocr Metab Disord. https://doi.org/10.1007/s11154-020-09592-3

19. Park JW, Kim DW, Kim D, Baek JW, Lee YJ, Baek HJ (2017) Korean thyroid imaging reporting and data system features of follicular thyroid adenoma and carcinoma: a single-center study. Ultrasonography 36(4):349-354

20. Liu BJ, Zhang YF, Zhao CK, Wang HX, Li MX, Xu HX (2020) Conventional ultrasound characteristics, TI-RADS category and shear wave speed measurement between follicular adenoma and follicular thyroid carcinoma. Clin Hemorheol Microcirc 75(3):291-301

21. Castellana M, Piccardo A, Virili C et al (2020) Can ultrasound systems for risk stratification of thyroid nodules identify follicular carcinoma? Cancer Cytopathol 128:250-259

22. Sillery JC, Reading CC, Charboneau JW, Henrichsen TL, Hay ID, Mandrekar JN (2010) Thyroid follicular carcinoma: sonographic features of 50 cases. AJR Am J Roentgenol 194(1):44-54

23. Ou D, Yao J, Jin J et al (2020) Ultrasonic identification and regression analysis of 294 thyroid follicular tumors. J Cancer Res Ther 16(5):1056-1062

24. Borowczyk M, Woliński K, Więckowska B et al (2021) Sonographic features differentiating follicular thyroid cancer from follicular adenoma-a meta-analysis. Cancers (Basel). https://doi.org/ 10.3390/cancers 13050938

25. Yoon JH, Kim EK, Youk JH, Moon HJ, Kwak JY (2014) Better understanding in the differentiation of thyroid follicular adenoma, follicular carcinoma, and follicular variant of papillary carcinoma: a retrospective study. Int J Endocrinol 2014:321595

26. Kim H, Shin JH, Hahn SY et al (2019) Prediction of follicular thyroid carcinoma associated with distant metastasis in the preoperative and postoperative model. Head Neck 41:2507-2513

27. Kuo TC, Wu MH, Chen KY, Hsieh MS, Chen A, Chen CN (2020) Ultrasonographic features for differentiating follicular thyroid carcinoma and follicular adenoma. Asian J Surg 43(1):339-346
28. Machens A, Holzhausen HJ, Dralle H (2005) The prognostic value of primary tumor size in papillary and follicular thyroid carcinoma. Cancer 103:2269-2273

29. Cibas ES, Ali SZ (2017) The 2017 Bethesda System for Reporting Thyroid Cytopathology. Thyroid 27:1341-1346

30. Wu MH, Chen KY, Hsieh MS, Chen A, Chen CN (2021) Risk stratification in patients with follicular neoplasm on cytology: use of quantitative characteristics and sonographic patterns. Front Endocrinol (Lausanne) 30(12):614630

31. Hong HS, Lee JY (2019) diagnostic performance of ultrasound patterns by K-TIRADS and 2015 ATA Guidelines in Risk Stratification of Thyroid Nodules and Follicular Lesions of Undetermined Significance. AJR Am J Roentgenol 213(2):444-450

32. Conzo G, Avenia N, Ansaldo GL et al (2017) Surgical treatment of thyroid follicular neoplasms: results of a retrospective analysis of a large clinical series. Endocrine 55:530-538

33. Słowińska-Klencka D, Wysocka-Konieczna K, Klencki M, Popowicz B (2020) Diagnostic value of six Thyroid Imaging Reporting and Data Systems (TIRADS) in cytologically equivocal thyroid nodules. J Clin Med 9(7):2281

34. Baser H, Cakir B, Topaloglu O et al (2017) Diagnostic accuracy of Thyroid Imaging Reporting and Data System in the prediction of malignancy in nodules with atypia and follicular lesion of undetermined significance cytologies. Clin Endocrinol (Oxf) 86(4):584-590

35. Pstrag N, Ziemnicka K, Bluyssen H, Wesoly J (2018) Thyroid cancers of follicular origin in a genomic light: in-depth overview of common and unique molecular marker candidates. Mol Cancer 17:116

36. Borowczyk M, Szczepanek-Parulska E, Dbicki S et al (2019) Differences in mutational profile between follicular thyroid carcinoma and follicular thyroid adenoma identified using next generation sequencing. Int J Mol Sci 20(13)

37. Zhang H, Zhang ZZ, Liu XD et al (2021) DNA methylation haplotype block markers efficiently discriminate follicular thyroid carcinoma from follicular adenoma. J Clin Endocrinol Metab 106(4):1011-1021

Publisher's note Springer Nature remains neutral with regard to jurisdictional claims in published maps and institutional affiliations. 